\title{
INFLUENCE OF CYP3A METABOLIZER STATUS ON THE PHARMACOKINETICS AND PHARMACODYNAMICS OF AMIODARONE
}

\author{
Stanislav Mičuda ${ }^{1}$, Martin Hodač ${ }^{2}$, Petr Pař̌zek ${ }^{2}$, Miloslav Pleskot ${ }^{2}$, Luděk Šišpera ${ }^{1}$, Jaroslav Cerman ${ }^{3}$, Jana Malákováa ${ }^{4}$, \\ Jirina Martínková ${ }^{1}$, Vladimír Pidrman ${ }^{2}$
}

Charles University in Prague; Faculty of Medicine in Hradec Králové: Department of Pharmacology ${ }^{1}$, Second Department of Internal Medicine ${ }^{2}$, Department of Medical Biochemistry3; University Teaching Hospital in Hradec Králové: Institute of Clinical Biochemistry and Diagnostics ${ }^{4}$

\begin{abstract}
Summary: The present work was designed to determine whether the individual differences in pharmacokinetics and pharmacodynamics of amiodarone and its $\mathrm{N}$-desethyl metabolite are related to cytochrome CYP3A metabolizer status. Methods: 12 cardiac patients with inducible ventricular tachyarrhythmias during the baseline electrophysiologic study were

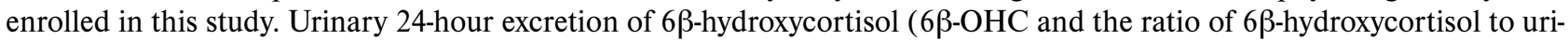
nary free cortisol ( $6 \beta$-OHC/UFC) were measured before the first amiodarone administration. Trough plasma concentrations of amiodarone and $\mathrm{N}$-desethylamiodarone (N-DEA) were measured after $79 \pm 11$ days ( $2^{\text {nd }}$ period) and after $182 \pm$ 25 days ( $3^{\text {rd }}$ period). Electrophysiologic effects of amiodarone therapy were established with serial electrophysiologic studies in 9 of these patients at the baseline and after $79 \pm 11$ days (during the second period). Results: Both the $6 \beta-\mathrm{OHC}$ excretion and $6 \beta-\mathrm{OHC} / \mathrm{UFC}$ ratio varied approximately 6 -fold between the patients. We found significant inverse correlation between the $6 \beta-\mathrm{OHC}$ excretion and the trough plasma concentrations of amiodarone at the time of the $3^{\text {rd }}$ period $\left(\mathrm{r}_{\mathrm{s}}=-0.58\right.$, $\mathrm{p}<0.05$ ). Similarly, there was correlation between the 24-hour urinary $6 \beta-\mathrm{OHC}$ excretion and trough plasma concentrations of amiodarone during the $3^{\text {rd }}$ period $\left(r_{s}=-0.64, p<0.025\right)$. We were unable to detect any association between CYP3A activity and amiodarone pharmacodynamics. Conclusion: This study points toward important information value of CYP3A metabolizer status in the context of therapeutic drug monitoring of amiodarone.
\end{abstract}

Key words: CYP3A, Amiodarone, $N$-desethylamiodarone, Cortisol, 6 $\beta$-hydroxycortisol

\section{Introduction}

Amiodarone is a class III antiarrhythmic agent with a delayed onset of action. Several weeks of treatment may be necessary before its maximal electrophysiologic effects become manifest $(1,2)$. Moreover, there are significant interpatient differences in both the pharmacokinetics and the antiarrhythmic effects after a standard dosage schedule of amiodarone (3). This makes it necessary to closely monitor all patients during amiodarone therapy.

To reveal the reason for such delay in the onset of action and the wide interpatient variability in therapeutic outcome, several studies have been conducted. According to their results the amiodarone major metabolite, N-desethylamiodarone, has been described as the most probable cause of this difference $(4,5)$. This metabolite is an electrophysiologically active compound with a pattern similar to that of its parent compound $(6,7)$. Moreover, peak antiarrhythmic activity of the drug correlates better with the time course of $\mathrm{N}$-desethylamiodarone concentrations than with amiodarone levels $(3,8)$. Taken together, it seems that conversion of amiodarone to $\mathrm{N}$-desethylamiodarone is the crucial step for the onset and progress of positive electrophysiological changes within the myocardium. Therefore, the activity of the converting enzyme may be an important determinant of the effectiveness of treatment. Consequently, subjects with low enzyme activity may be nonresponders to such therapy.

The only enzymes involved in the conversion of amiodarone to N-desethylamiodarone are enzymes of the cytochrome CYP3A subfamily (9). This subfamily represents the major group of human hepatic cytochrome P450. Many drugs in common use are substrates of this cytochrome (10). Nevertheless, interindividual variability in the expression of CYP3A is very high (20- to 40-fold) (11), which accounts for large interindividual differences in the disposition and consequently in the efficacy and safety of some drugs that are metabolized by CYP3A (12). It has therefore been suggested that in such cases, administration of a probe drug to assess CYP3A activity could help to guide therapy. A number of CYP3A substrates have been investigated as potential in vivo probes, such as the erythromycin breath test (ERMBT) (13) and the midazolam clearance (14). As an alternative to use of these probe drugs, measurement of changes in the disposition of an endogenous sub- 
stance, which is metabolized by investigated enzyme, has been attempted by some investigators. The urinary output of $6 \beta$-hydroxycortisol ( $6 \beta-\mathrm{OHC})$ has been successfully employed in this way for the assessment of CYP3A induction by drugs such as phenobarbital, antipyrin, rifampicin, phenytoin, and carbamazepin $(15,16,17)$. Conversely, the potent enzyme inhibitors cimetidine and ketoconazole have been shown to decrease $6 \beta-\mathrm{OHC}$ excretion $(18,19)$. Moreover, Ged et al. found a high correlation between the urinary level of $6 \beta-\mathrm{OHC}$ and liver microsomal cortisol $6 \beta$ hydroxylase activity and hepatic CYP3A activity. Thus, $6 \beta$ $\mathrm{OHC}$ excretion can by used as an in vivo marker of CYP3A activity. To adjust for diurnal and interindividual differences in adrenal cortisol production, 24-hour urine collections may by used or $6 \beta-\mathrm{OHC}$ excretion should be expressed as its ratio to urinary free cortisol ( $6 \beta-\mathrm{OHC} / \mathrm{UFC})$ (20).

In this study, we tested the hypothesis that interpatient differences in the pharmacokinetics and pharmacodynamics of oral amiodarone may at least in part reflect heterogeneity in CYP3A activity. Using 24-hour urinary $6 \beta-\mathrm{OHC}$ excretion and the $6 \beta-\mathrm{OHC} / \mathrm{UFC}$ ratio, we prospectively measured CYP3A catalytic activity in amiodarone-treated cardiac patients to determine if the results of $6 \beta-\mathrm{OHC} / \mathrm{UFC}$ would predict interpatient variation in: (A) the observed trough blood levels of amiodarone or N-desethylamiodarone, (B) pharmacodynamic parameters.

\section{Material and Methods}

The protocol for the study was approved by the Human Ethics Committee of the Charles University Teaching
Hospital in Hradec Králové. All subjects participating in the study gave signed, written informed consent. The study was conducted at the Second Department of Internal Medicine in Hradec Králové.

Patients. Twelve patients (only men) were enrolled in the study. All had recurrent symptomatic ventricular arrhythmias that were reproducibly induced during a baseline electrophysiologic study. Their ages ranged from 41 to 75 years (median age, 63). The clinical features of these patients are presented in Table 1. Exclusion criteria included history of amiodarone therapy during the last 1 year, hepatic dysfunction, congestive heart failure and treatment with any known inhibitor or inducer of CYP3A.

Study design. This was an open, three-period study. Patients who were likely to benefit from amiodarone therapy were considered for enrolment.

During the first period, patients were hospitalized and baseline electophysiologic studies were performed. Exactly at 6:00 AM the following morning, patients emptied their bladders. Urine was then collected over a 24-hour period. Immediately after the urine collection, patients started amiodarone treatment with a loading dose of $800 \mathrm{mg} /$ day (four tablets of $200 \mathrm{mg}$ Cordarone) for 14 days. The daily dosage was then reduced to $600 \mathrm{mg}$ for the next 14 days, followed by a maintenance dose of $400 \mathrm{mg}$ amiodarone each day.

Patients continued to receive amiodarone for a mean of $79 \pm 11$ days (range, 67 to 99 days), until they were hospitalized for the second period. During this period, follow-up electrophysiologic studies were performed, and one venous blood sample for the determination of amiodarone and $\mathrm{N}$ desethylamiodarone plasma concentration was drawn just before the next amiodarone administration.

Tab. 1: Characteristics of study patients.

\begin{tabular}{|c|c|c|c|c|c|c|c|c|}
\hline \multirow{2}{*}{$\begin{array}{c}\text { Patient } \\
\text { No. }\end{array}$} & \multirow{2}{*}{$\begin{array}{c}\text { Age } \\
\text { (years) }\end{array}$} & \multirow[t]{2}{*}{ Diagnosis } & \multirow[t]{2}{*}{ Arrhythmia } & \multicolumn{2}{|c|}{ I. phase } & \multicolumn{2}{|c|}{ II. phase } & \multirow{2}{*}{$\frac{\text { III. phase }}{\mathrm{Pk}}$} \\
\hline & & & & Pht & $\mathrm{EP}_{\mathrm{B}}$ & $\mathrm{Pk}$ & $\mathrm{EP}_{\mathrm{F}}$ & \\
\hline 1. & 51 & CAD, MI & nonsustained VT & + & + & + & + & - \\
\hline 2. & 75 & CAD & VF & + & + & + & + & + \\
\hline 3. & 67 & CAD & nonsustained VT & + & + & + & + & + \\
\hline 4. & 72 & CAD, MI & SUO & + & + & + & + & + \\
\hline 5. & 65 & $\mathrm{CM}$ & sustained VT & + & + & + & + & + \\
\hline 6. & 62 & $\mathrm{CAD}, \mathrm{MI}$ & sustained VT & + & + & + & - & + \\
\hline 7. & 59 & CAD, MI & $\mathrm{VF}$ & + & + & + & + & + \\
\hline 8. & 54 & CAD & SUO & + & + & + & - & + \\
\hline 9. & 61 & CAD, MI & nonsustained VT & + & + & + & + & - \\
\hline 10. & 41 & $\mathrm{CM}$ & SUO & + & + & + & + & + \\
\hline 11. & 64 & CAD & sustained VT & + & + & + & + & + \\
\hline 12. & 74 & CAD & VF & + & + & + & - & + \\
\hline
\end{tabular}

CAD - coronary artery disease, MI - myocardial infarction; CM - cardiomyopathy; VF - documented ventricular fibrillation; sustained VT - documented symptomatic sustained ventricular tachycardia; nonsustained VT - documented symptomatic nonsustained ventricular tachycardia; SUO - syncope of unknown origin with inducible tachyarrhythmia; Pht measurement of urinary free cortisol and $6 \beta$-hydroxycortisol; $\mathrm{EP}_{\mathrm{B}}$ - baseline electrophysiologic study; $\mathrm{EP}_{\mathrm{F}}$ - follow-up electrophysiologic study; $\mathrm{Pk}$ - measurement of amiodarone and $\mathrm{N}$-desethylamiodarone plasma concentrations; $+=$ patient underwent this measurement; - = patient omitted this evaluation. 
After $182 \pm 25$ days (range, 152 to 223 days) from the start of amiodarone therapy, 10 patients underwent the third phase of this study. It consisted only of collection of one venous blood sample for the determination of amiodarone and $\mathrm{N}$-desethylamiodarone plasma concentration as described above.

Electrophysiologic study. All patients underwent a baseline electrophysiologic study after all antiarrhythmic drugs had been discontinued for at least 5 half-lives. Surface ECG was recorded simultaneously with intracardiac electrograms from the high atrium, His bundle recording site, and right ventricular apex (EPLab, Quinton). Electrophysiologic intervals were determined from the mean of five successive cycles during both sinus rhythm and constant rate pacing. Cardiac pacing was performed with a programmable stimulator (UHS 20, Biotronic). Our ventricular stimulation protocol has been previously reported (21) and consists of serial introduction of 1,2 , and 3 premature ventricular extrastimuli introduced during both sinus rhythm and ventricular pacing at cycle lengths of 600, 500 and 429 $\mathrm{ms}$. The stimulus was a rectangular impulse (1 $\mathrm{ms}$ in duration) delivered at twice the diastolic threshold. Stimulation was performed at the right ventricular apex in all patients, and if no arrhythmia was induced, then at the right ventricular outflow tract. The end point was the induction of sustained ventricular tachycardia or fibrillation or completion of the protocol. Patients with sustained monomorphic ventricular tachycardia induced at any point in the stimulation protocol and those with sustained polymorphic ventricular tachycardia or ventricular fibrillation induced by 1 or 2 extrastimuli were candidates for amiodarone therapy. Followup electrophysiologic studies were performed using the same stimulation protocol as in the baseline study. Nine patients agreed to undergo a follow-up electrophysiologic test.

Responses to stimulation during the baseline and follow-up studies were categorized as: (A) sustained ventricular tachycardia VT; defined as a tachycardia which lasted more than 30 seconds or required termination prior to that time because of hemodynamically significant symptoms, (B) non-sustained VT; defined as a tachycardia which lasted less than 30 seconds, and $(\mathrm{C})$ ventricular fibrillation VF; defined as the induced rhythm when, within 3 seconds of the initiation of a ventricular tachyarrhythmia, the intracardiac electrogram showed VF.

Measurement of enzyme activity. The activity of CYP3A was estimated either as the ratio of urinary $6 \beta$-hydroxycortisol to urinary free cortisol $(6 \beta-\mathrm{OHC} / \mathrm{UFC})$ or as the amount of 24-hour urinary $6 \beta$-OHC excretion. Urine was collected over a 24-hour period before dosing in a single container. The total voided volume was measured, and aliquots were frozen and stored at $-20{ }^{\circ} \mathrm{C}$. The concentrations of $6 \beta$-hydroxycortisol in urine were measured with an HPLC method previously described (22). The CORTISOL RIA kit (IMMUNOTECH, Prague, Cat. No. 1841) was used for the determination of cortisol in urine samples (di- rectly, without extraction). This RIA system is based on specific monoclonal antibody-coated tubes and a ${ }^{125}$ I-labelled cortisol tracer.

Amiodarone and $\mathrm{N}$-desethylamiodarone plasma concentration. Amiodarone and $\mathrm{N}$-desethylamiodarone plasma concentrations were determined by a high-performance liquid chromatographic method (23).

Statistical analysis. Nonparametric statistical tests were used to analyze these data. The Spearman rank correlation test was used to determine the degree of association between pharmacokinetic or pharmacodynamic parameters of amiodarone therapy and CYP3A metabolizer status. For amiodarone pharmacokinetics prediction, the dependent variables chosen were the amiodarone and N-desethylamiodarone whole-blood trough concentrations alone or divided by the total cumulative dose (mg) of drug received. A $p$ value less than 0.05 was regarded as statistically significant. In the enzyme activity-effect relation, the effect was transformed by use of the relative change from baseline values computed as follows:

$$
E=\frac{E_{i}}{E_{0}}
$$

in which $E_{i}$ is the value of the electrophysiologic effect at time $i$, and $E_{0}$ is the corresponding value at baseline. The pharmacodynamic data before and during amiodarone therapy were compared with use of the Wilcoxon matched-pairs signed-rank test. All data are reported as the median and range.

\section{Results}

Amiodarone was well tolerated in all patients. Of 12 consecutive consenting patients seen during a 30-month period, three declined to undergo follow-up electrophysiologic tests during the second period, and two discontinued amiodarone treatment before the third phase (Tab. 1). Seven patients entirely completed the study.

All urinary samples could be analyzed for the determination of $6 \beta$-hydroxycortisol and free cortisol. There were comparably high interindividual differences among the subjects investigated. The urinary $6 \beta-\mathrm{OHC} / \mathrm{UFC}$ ratios ranged from 2.5 to 13.2 (median, 4.29) and the 24-hour excretions of $6 \beta-O H C$ were within the interval 215.6 to $1161 \mathrm{nmol} / 24 \mathrm{~h}$ (median, $729 \mathrm{nmol} / 24 \mathrm{~h}$ ), both corresponding to a six-fold difference. Nevertheless, there was a significant correlation between both parameters $(r=0.73, p<0.01$, Fig. 1$)$.

The maintenance dose of amiodarone was $400 \mathrm{mg} /$ day. The time dependence of amiodarone and N-desethylamiodarone concentrations and N-DEA/amiodarone ratios are shown in Fig. 2. During the second period trough plasma concentrations of amiodarone and $\mathrm{N}$-desethylamiodarone ranged from 0.6 to $1.99 \mathrm{mg} / \mathrm{L}$ (median, $1.4 \mathrm{mg} / \mathrm{L}$ ) and 0.47 to $1.45 \mathrm{mg} / \mathrm{L}$ (median, $0.96 \mathrm{mg} / \mathrm{L}$ ), respectively. Trough plasma concentrations of amiodarone and N-desethylamiodarone during the third period ranged from 0.92 to 2.94 


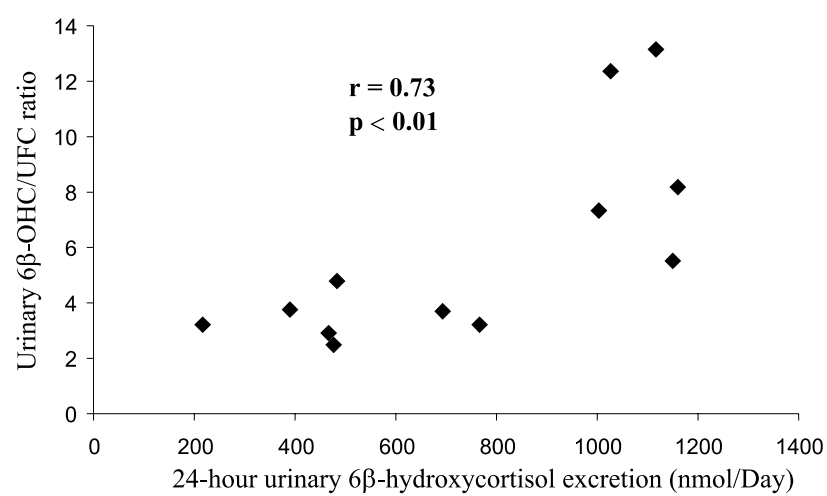

Fig. 1: Correlation between the 24-hour urinary 6 $\beta$-hydroxycortisol excretion and urinary $6 \beta$-hydroxycortisol/free cortisol ratio ( $6 \beta-\mathrm{OHC} / \mathrm{UFC})$ in 12 patients.
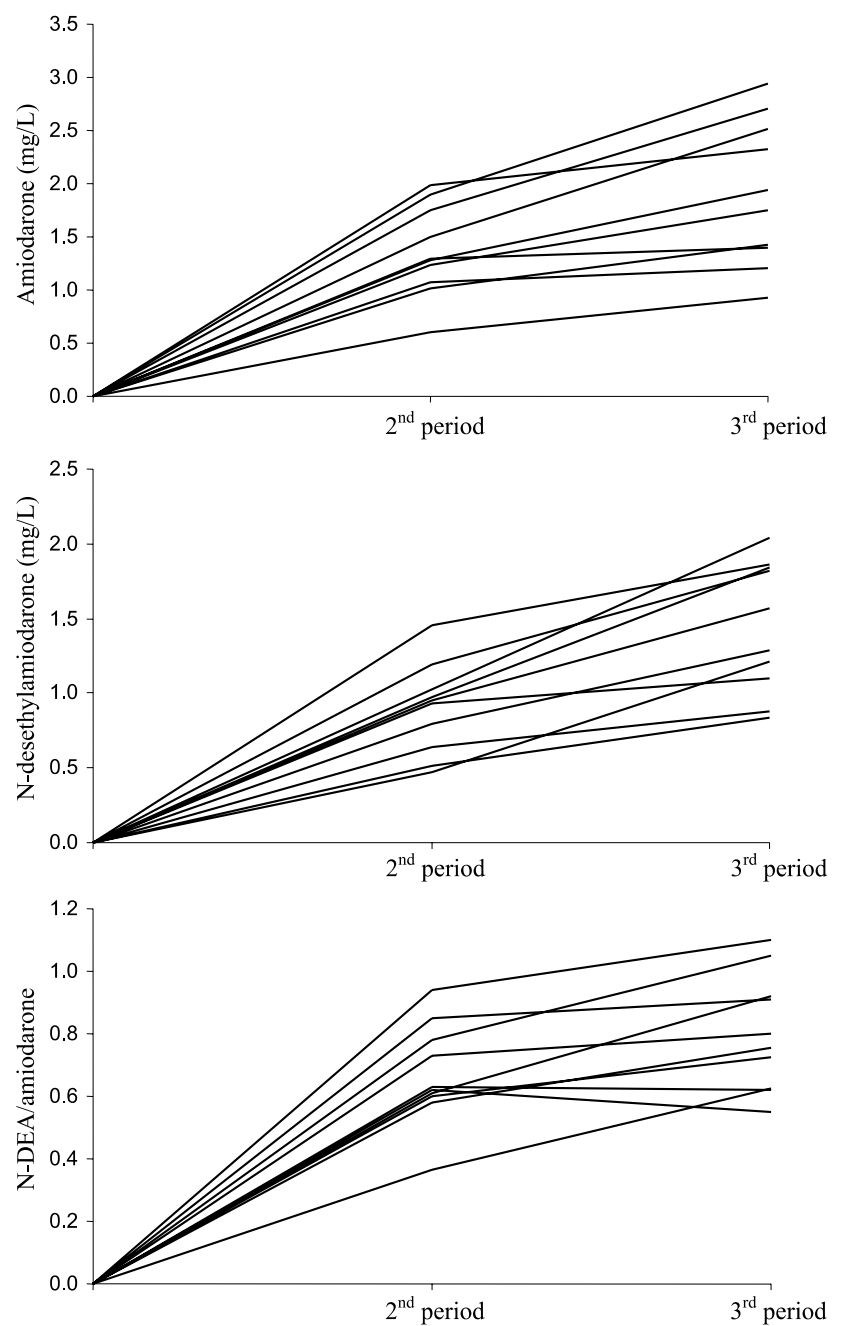

Fig. 2: Plots of time-dependence of plasma amiodarone and $\mathrm{N}$-desethylamiodarone (N-DEA) concentrations and $\mathrm{N}$ DEA/amiodarone ratios in 10 patients. $2^{\text {nd }}$ period $=79 \pm 11$ days; $3^{\text {rd }}$ period $=182 \pm 25$ days of amiodarone therapy. $\mathrm{mg} / \mathrm{L}$ (median, $1.85 \mathrm{mg} / \mathrm{L}$ ) and 0.84 to $2.04 \mathrm{mg} / \mathrm{L}$ (median, $1.43 \mathrm{mg} / \mathrm{L}$ ), respectively. There was a significant increase in both the plasma amiodarone $(\mathrm{p}<0.003)$ and N-desethylamiodarone $(\mathrm{p}<0.003)$ concentrations between the second and third phases. Moreover, median N-DEA/amiodarone concentration ratios significantly increased $(p<0.02)$ from the second periods 0.63 (range, 0.37 to 0.94 ) to the third periods 0.78 (range, 0.44 to 1.1 ). The basic electrophysiologic data of the atria, AV nodes and ventricles are presented in Tab. 2. After $79 \pm 11$ days of amiodarone therapy, significant increases of $\mathrm{AV}$ nodal effective refractory period $(p<0.036)$, ventricular effective refractory period $(p<$ $0.014)$, and corrected QT interval ( $\mathrm{p}<0.034)$ were observed. We were unable to find an association between amiodarone or N-DEA plasma concentrations and changes in electrophysiologic parameters (Tab. 3).

In general, no correlations were found between either the $6 \beta-\mathrm{OHC} / \mathrm{UFC}$ ratio or the 24-hour urinary excretion of $6 \beta-\mathrm{OHC}$ at the baseline and amiodarone pharmacokinetics or pharmacodynamics (Tab. 4). The exception was an inverse relationships between the $6 \beta-\mathrm{OHC} / \mathrm{UFC}$ ratio and the

Tab. 2: Electrophysiologic effects of amiodarone in 9 patients.

\begin{tabular}{|l|c|c|c|}
\hline & Baseline & Follow-up & p \\
\hline SSCL & $1009(541-1248)$ & $1058(695-1453)$ & 0.07 \\
\hline AERP & $280(240-360)$ & $320(300-400)$ & 0.36 \\
\hline AVERP & $300(220-480)$ & $420(320-520)$ & 0.036 \\
\hline QTc & $418(357-502)$ & $430(354-490)$ & 0.014 \\
\hline VERP & $280(200-320)$ & $330(220-380)$ & 0.034 \\
\hline
\end{tabular}

Values are median values $(\mathrm{msec})$; range is given in parentheses (msec).

SSCL - spontaneous sinus cycle length; AERP - atrial effective refractory period; AVERP - AV nodal effective refractory period; QTc - QT interval corrected by spontaneous sinus cycle length; VERP - ventricular effective refractory period.

Tab. 3: Concentration-effect relations in 9 patients.

\begin{tabular}{|l|c|c|c|c|}
\hline & \multicolumn{2}{|c|}{ Amiodarone (mg/L) } & \multicolumn{2}{c|}{ A-DEA (mg/L) } \\
& $\mathbf{r}_{\mathbf{s}}$ & $\mathbf{p}$ & $\mathbf{r}_{\mathbf{s}}$ & $\mathbf{p}$ \\
\hline $\mathbf{E}_{\text {SSCL }}$ & -0.4 & 0.15 & -0.56 & 0.1 \\
\hline $\mathbf{E}_{\text {AERP }}$ & -0.07 & 0.45 & -0.2 & 0.35 \\
\hline $\mathbf{E}_{\text {AVERP }}$ & 0.12 & 0.45 & -0.25 & 0.35 \\
\hline $\mathbf{E}_{\text {QTc }}$ & 0.57 & 0.1 & 0.15 & 0.4 \\
\hline $\mathbf{E}_{\text {VERP }}$ & -0.52 & 0.1 & -0.53 & 0.1 \\
\hline
\end{tabular}

$\mathrm{E}_{\mathrm{Y}}$ - change in electrophysiologic parameter $\mathrm{Y}$ (followup/baseline); SSCL - spontaneous sinus cycle length; AERP - atrial effective refractory period; AVERP - AV nodal effective refractory period; VERP - ventricular effective refractory period; QTc - QT interval corrected by spontaneous sinus cycle length. 
Tab. 4: Relations between CYP3A activity and amiodarone pharmacokinetics and pharmacodynamics.

\begin{tabular}{|c|c|c|c|c|}
\hline & \multicolumn{2}{|c|}{ 6 $\beta-\mathrm{OHC} / \mathrm{UFC}$} & \multicolumn{2}{|c|}{$\begin{array}{c}6 \beta-O H C \\
(\mathrm{nmol} / 24 \mathrm{~h})\end{array}$} \\
\hline & $\mathbf{r}_{\mathrm{s}}$ & p & $\mathbf{r}_{\mathrm{s}}$ & p \\
\hline $\mathrm{C}_{\text {amiodarone }}{ }^{1 *}$ & -0.35 & 0.15 & -0.2 & 0.3 \\
\hline $\mathrm{C}_{\text {amiodarone }}{ }^{2 *}$ & -0.58 & 0.05 & -0.64 & 0.025 \\
\hline $\mathrm{C}_{\mathrm{N} \text {-DEA }}{ }^{1 *}$ & -0.36 & 0.15 & 0.05 & 0.4995 \\
\hline $\mathrm{C}_{\mathrm{N}-\mathrm{DEA}}{ }^{2 *}$ & -0.43 & 0.15 & -0.14 & 0.49 \\
\hline $\mathrm{C}_{\mathrm{N}-\mathrm{DEA}} / \mathrm{C}_{\text {amiodarone }}{ }^{1 *}$ & 0.28 & 0.2 & 0.25 & 0.25 \\
\hline $\mathrm{C}_{\mathrm{N}-\mathrm{DEA}} / \mathrm{C}_{\text {amiodarone }}{ }^{2 *}$ & 0.25 & 0.25 & 0.56 & 0.05 \\
\hline $\mathbf{E}_{\mathrm{SSCL}}{ }^{* *}$ & 0.25 & 0.3 & 0.03 & 0.475 \\
\hline $\mathbf{E}_{\mathrm{AERP}}{ }^{* *}$ & 0.43 & 0.15 & -0.5 & 0.15 \\
\hline $\mathbf{E}_{\text {AVERP }}{ }^{* * *}$ & -0.12 & 0.45 & -0.29 & 0.3 \\
\hline $\mathrm{E}_{\mathrm{QTc}^{* *}}$ & -0.36 & 0.25 & -0.39 & 0.2 \\
\hline $\mathbf{E}_{\text {VERP }}{ }^{* *}$ & -0.1 & 0.495 & -0.24 & 0.3 \\
\hline
\end{tabular}

$\mathrm{C}_{\mathrm{X}}$ - concentrations of $\mathrm{X}(\mathrm{mg} / \mathrm{L}) ;{ }^{1}$ - measurements in the $2^{\text {nd }}$ phase; ${ }^{2}-$ measurements in the $3^{\text {rd }}$ phase; $E_{Y}-$ change in electrophysiologic parameter $\mathrm{Y}$ (follow-up/baseline); SSCL - spontaneous sinus cycle length; AERP - atrial effective refractory period; AVERP - AV nodal effective refractory period; VERP - ventricular effective refractory period; QTc - QT interval corrected by spontaneous sinus cycle length; ${ }^{*} \mathrm{n}=10$ patients (Tab. 1 ); ${ }^{* *} \mathrm{n}=9$ patients (Tab. 1 ).
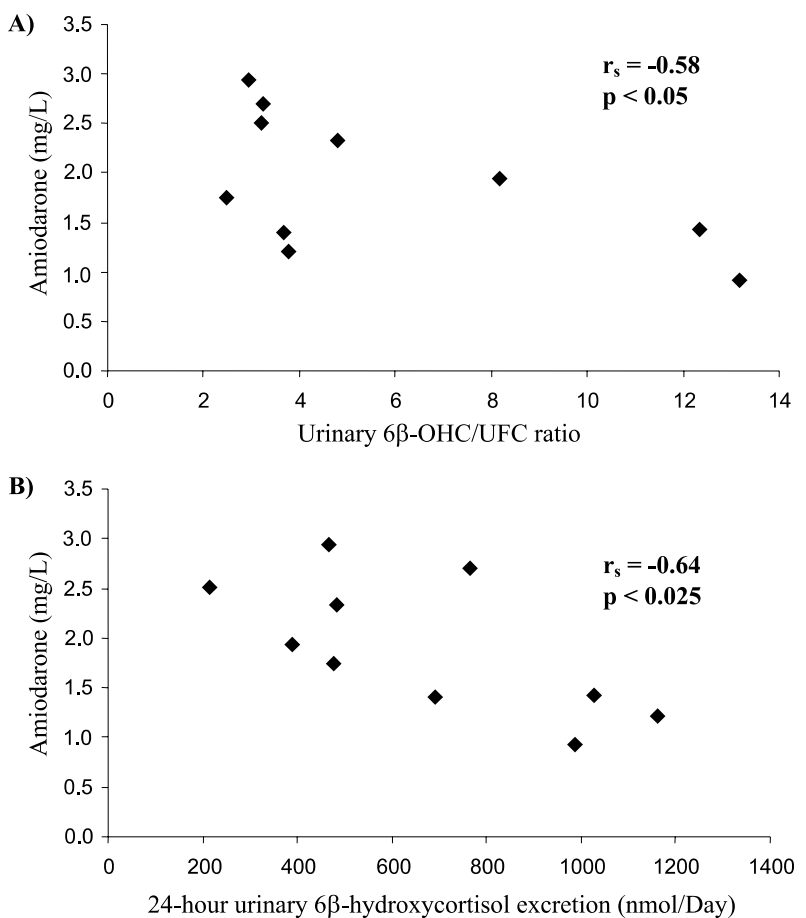

Fig. 3: (A) Relationships between the urinary $6 \beta$-hydroxycortisol/free cortisol ratio ( $6 \beta$-OHC/UFC) and the trough plasma concentrations of amiodarone in the $3^{\text {rd }}$ period. (B) Relationships between the 24-hour urinary $6 \beta$-hydroxycortisol excretion and the trough plasma concentrations of amiodarone in the $3^{\text {rd }}$ period. trough plasma concentrations of amiodarone in the $3^{\text {rd }}$ pe$\operatorname{riod}\left(r_{s}=-0.58, p<0.05\right.$, Fig. 3$)$. Correlations were also seen between 24-hour urinary $6 \beta-\mathrm{OHC}$ excretion and either trough plasma concentration of amiodarone in the $3^{\text {rd }}$ period $\left(r_{s}=-0.64, p<0.025\right.$, Fig. 3$)$ or N-DEA/amiodarone ratio in the $3^{\text {rd }}$ period $\left(\mathrm{r}_{\mathrm{s}}=0.56, \mathrm{p}<0.05\right)$.

\section{Discusion}

We found a significant correlation between the CYP3A activity, as measured by the $6 \beta-\mathrm{OHC} / \mathrm{UFC}$ ratio or 24-hour urinary $6 \beta-\mathrm{OHC}$ excretion, and the trough blood level of amiodarone. These correlations, as expected, were inverse. Thus, patients with a higher $6 \beta-\mathrm{OHC} / \mathrm{UFC}$ ratio or higher 24-hour urinary $6 \beta-\mathrm{OHC}$ excretion, reflecting greater CYP3A activity, generally had lower trough amiodarone levels at a given standard dose. This supports our hypothesis that variability in the catalytic activity of CYP3A accounts, in part, for the interpatient difference in the pharmacokinetics of amiodarone.

The use of the $6 \beta-\mathrm{OHC} / \mathrm{UFC}$ ratio as a marker for the determination of CYP3A activity has been debated. Only very recently several authors have simultaneously clearly reported limitations in the applications and interpretation of this method $(24,25,26,27)$. First, cortisol is a substrate for both CYP3A isoforms present in adult humans, e.g. CYP3A4 and CYP3A5 (28); accordingly, using this probe assay, metabolism of whole CYP3A is measured. Therefore, if the drug is metabolized by only one of the CYP3A isoforms or the contribution of both isoforms is poorly understood, such nonselectivity in probe-reaction results in an overestimation of overall CYP3A activity. However, to what extent CYP3A5 contributes to the production of $6 \beta$-hydroxycortisol is currently unknown. It is unlikely that CYP3A5 would mask changes in CYP3A4 activity because it has not been shown to be inducible (28) and is present in much smaller concentrations than CYP3A4 $(24,29)$. A second potential limitation of the urinary $6 \beta$-hydroxycortisol/free cortisol ratio is that it reflects CYP3A-mediated metabolism in the liver as well as in extrahepatic tissues $(30,31)$. For example, in one study involving a patient undergoing liver transplantation, the $6 \beta$-hydroxycortisol/free cortisol ratio fell during the anhepatic phase, but only to approximately $50 \%$ of pre-operative levels (32). Despite all these potentially confusing factors, experience with diagnostic inducers and inhibitors $(16,17,19,24,33)$ clearly revealed that the urinary ratio of $6 \beta-\mathrm{OHC} / \mathrm{UFC}$ and 24 -hour urinary $6 \beta$-hydroxycortisol excretion are useful parameters for the measurement of CYP3A activity. Moreover, this assay has important advantages over other markers in that it is noninvasive and it requires no drug administration. Thus, we decided to use this method in the cases of our seriously ill cardiac patients.

Concerning the pattern of absolute amiodarone levels, a more than 3-fold interpatient differences has been observed during both periods. These results are consistent with 
previously reported findings (3). According to our results, such variability could be at least in part attributable to CYP3A activity. However, the enzyme activity-trough blood amiodarone levels correlation was less significant at the time of the second period than at time of the third period. This probably reflects the changes in the prescribed daily doses during the first four weeks after amiodarone therapy initiation (loading dose). Patients may therefore not have been at a steady state at the time of the second period. In contrast, no significant correlation was shown between CYP3A activity and N-desethylamiodarone plasma concentration. This disassociation may be because the plasma $\mathrm{N}$-desethylamiodarone levels are determined not only by the rate of $\mathrm{N}$-deethylation but also by its further elimination. A large part of the formed N-DEA is excreted in bile in a conjugated form (34). Therefore the $6 \beta$-hydroxycortisol test does not predict the plasma concentrations of N-DEA.

In contrast to the kinetic data, the results of the present study point toward other factors than CYP3A metabolizer status as the major determinant of the interindividual variation in amiodarone pharmacodynamics. These data are difficult to explain because no similar studies have been conducted with amiodarone. We are well aware that the number of patients studied is small in view of the many confusing factors such as age, gender, environmental agents and drugs. On the other hand, most of these factors remain constant during the study. Therefore, the most probable explanation for our results is that both amiodarone and its major metabolite have unusual pharmacokinetics which have still not allowed us to clearly establish the relation to clinical efficacy. Several investigators have found a clear concentration-related effect of amiodarone and especially $\mathrm{N}-\mathrm{DEA}$ on AV node and ventricular function refractory period prolongation, and suppression of atrial and ventricular arrhythmias $(3,8,34)$. Conversely, our data, together with findings reported by others $(35,36,37)$, demonstrate that plasma concentrations of amiodarone and its active metabolite within the ranges observed are not a useful guide to the electrophysiologic effects of the drug during long-term therapy. Regardless, these findings provide no basis for the measurement of CYP3A activity as an indicator for amiodarone therapeutic outcome.

Clinical implications. Several investigators have shown that plasma amiodarone levels of more than $2.5 \mathrm{mg} / \mathrm{L}$ correlate with an increased incidence of adverse drug effects $(35,38,39)$. Use of amiodarone at conventional dosages together with potent inhibitors of CYP3A therefore carries an enhanced risk of thyroid, hepatic, gastrointestinal and dermatological toxicity.

In conclusion, this study shows that the CYP3A metabolizer status significantly affects the steady state plasma concentration of amiodarone. We suggest that CYP3A catalytic activity should be taken into consideration in amiodarone treatment of patients, who have a low activity of these enzymes or who are going to be medicated with drugs, which are inhibitors or substrates for CYP3A.

\section{Acknowledgements}

We acknowledge the study personnel at the Second Department of Internal Medicine and at the Department of Pharmacology in Hradec Králové, for their assistance in completing this study.

This research was supported by grant GAUK (No. 57/1997/C) of the Charles University in Prague.

\section{References}

1. Rosenheck S, Sousa J, Calkins H, Schmaltz S, DeBuitleir M, Kadish AH, Morady F. Comparison of the results of electrophysiologic testing after short-term and long term treatment with amiodarone in patients with ventricular tachycardia. Am Heart J 1991;121:1693-98.

2. Kadish AH, Marchlinksi FE, Josephson ME, Buxton AE. Amiodarone: correlation of early and late electrophysiologic studies with outcome. Am Heart J 1986;112:1134-40.

3. Mitchell LB, Wyse G, Gillis AM, Duff HJ. Electropharmacology of amiodarone therapy initiation. Time courses of onset of electrophysiologic and antiarrhythmic effects. Circulation 1989;80:34-42.

4. Nattel S. Pharmacodynamic studies of amiodarone and its active $\mathrm{N}$-desethyl metabolite. J Cardiovasc Pharmacol 1986;8:771-7.

5. Talajic M, DeRoode MR, Nattel S. Comparative electrophysiologic effects of intravenous amiodarone and desethylamiodarone in dogs: Evidence for clinically relevant activity of the metabolite. Circulation 1987;75:265-71

6. Nattel S, Davies M, Quantz M. The antiarrhythmic efficacy of amiodarone and desethylamiodarone, alone and in combination, in dogs with acute myocardial infarction. Circulation 1988;77:200-8

7. Yabek SM, Kato R, Singh BN. Effects of amiodarone and its metabolite, desethylamiodarone, on the electrophysiologic properties of isolated cardiac muscle. J Cardiovasc Pharmacol 1986;8:197-207.

8. Tieleman RG, Gosselink M, Crijns HJGM, VanGelder I, VandenBerg MP, DeKam PJ, VanGilst WH, Lie KI. Efficacy, safety, and determinants of conversion of atrial fibrillation and flutter with oral amiodarone. Am J Cardiol 1997;79:53-7.

9. Fabre G, Julian B, Saint-Aubert B, Joyeux H, Berger Y. Evidence for CYP3A-mediated N-deethylation of amiodarone in human liver microsomal fractions. Drug Metab Dispos 1993;21:978-85.

10. Rendic S, DiCarlo FJ. Human cytochrome P450 enzymes: a status report summarizing their reactions, substrates, inducers and inhibitors. Drug Metab Rev 1997;29:413-580.

11. Shimada T, Yamazaki H, Mimura M, Inui Y, Guengerich FP. Interindividual variations in human liver cytochrome P-450 enzymes involved in the oxidation of drugs, carcinogens and toxic chemicals: studies with liver microsomes of 30 Japanese and 30 Caucasians. J Pharmacol Exp Ther 1994;270:414-23.

12. Lown KS, Thummel KE, Benedict PE, Shen DD, Turgeon DK, Berent S, Watkins PB. The erythromycin breath test predicts the clearance of midazolam. Clin Pharmacol Ther 1995;57:16-24.

13. Watkins PB. Noninvasive test of CYP3A enzymes. Pharmacogenetics 1994;38:82-9.

14. Thummel KE, O'Shea D, Paine MF, Shen DD, Kunze KL, Perkins JD, Wilkinson GR. Oral first-pass elimination of midazolam involves both gastrointestinal and hepatic CYP3A-mediated metabolism. Clin Pharmacol Ther 1996;59:491-502.

15. Ohnhaus EE, Park BK. Measurement of urinary 6-beta-hydroxycortisol excretion as an in vivo parameter in the clinical assessment of the microsomal enzyme-inducing capacity of antipyrine, phenobarbitone and rifampicin. Eur J Clin Pharmacol 1979;15:139-45.

16. Ohnhaus EE, Breckeridge AM, Park BK. Urinary excretion of $6 \beta$-hydroxycortisol and the time course measurement of enzyme induction in man. Eur $\mathbf{J}$ Clin Pharmacol 1989;36:39-46.

17. Tomlinson B, Young RP, Ng MCY, Anderson PJ, Kay R, Critchley JAJH. Selective liver enzyme induction by carbamazepine and phenytoin in Chinese epileptics. Eur J Clin Pharmacol 1996;50:411-5.

18. Park BK. Assessment of urinary 6 6 -hydroxycortisol as in vivo index of mixed function oxygenase activity. Br J Clin Pharmacol 1981;12:97-102.

19. Zürcher RM, Frey BM, Frey FJ. Impact of ketoconazole on the metabolism of prednisolon. Clin Pharmacol Ther 1989;45:366-72.

20. Saenger P. 6 6 -Hydroxycortisol in random urine samples as an indicator of enzyme induction. Clin Pharmacol Ther 1983:34:818-21.

21. Pleskot M, Pařízek P, Hodač M, Haman L, Štásek J, Červinka P, Tauchman M. Revascularization of the myocardium and electrical instability of the ventricles. Vnitř Lék 1999;45:75-80.

22. Lee $\mathrm{CH}$. Urinary $6 \beta$-hydroxycortisol in humans: analysis, biological variations, and reference ranges. Clin Biochem 1995;28:49-54. 
23. Kopecká J, Palička V. Liquid-chromatographic determination of amiodarone and $\mathrm{N}$-desethylamiodarone in serum. Ninth Conference of Young Biochemists in Jánské Lázně, May 20-22, 1996.

24. Kovacs SJ, Martin DE, Everitt DE, Patterson SD, Jorkasky DK. Urinary excretion of $6 \beta$-hydroxycortisol as in vivo marker for CYP3A induction: applications and recommendations. Clin Pharmacol Ther 1998;63:617-22.

25. Beyeler C, Frey BM, Bird HA. Urinary $6 \beta$-hydroxycortisol excretion in rheumatoid arthritis. Br J Rheumatol 1997;36:54-8.

26. Kinirons MT, O'Shea D, Kim RB, Groopman JD, Thummel KE, Wood AJJ, Wilkinson GR. Failure of erythromycin breath test to correlate with midazolam clearance as a probe of cytochrome P4503A. Clin Pharmacol Ther 1999;66:224 31.

27. Seidegard J, Dahlstrom K, Kullberg A. Effect of grapefruit juice on urinary $6 \beta$ hydroxycortisol/cortisol excretion. Clin Exp Pharm Physiol 1998;25:379-81

28. Wrighton SA, Brian WR, Sari MA, Iwasaki M, Guengerich FP, Raucy JL. Studies on the expression and metabolic capabilities of human liver cytochrome P450IIIA5 (HLp3). Mol Pharmacol 1990;38:207-13

29. Wrighton SA, Ring BJ, Watkins PB, VanderBranden M. Identification of a polymorphically expressed member of the human cytochrome P-450III family. Mo Pharmacol 1989;36:97-105.

30. Murray GI, Barnes TS, Sewell HF. The immunocytochemical localisation and distribution of cytochrome P-450 in normal human hepatic and extrahepatic tissues with a monoclonal antibody to human cytochrome P-450. Br J Clin Pharmacol 1988;25:465-75.

31. Schuetz EG, Schuetz JD, Grogan WM, Naray A, Fejes AG, Toth AG, Raucy J. Expression of cytochrome P4503A in amphibian rat and human kidney. Arch Biochem Biophys 1992;294:206-14

32. Watkins PB, Turgeon DK, Saenger P. Comparison of urinary $6 \beta$-cortisol and the erythromycin breath test as measures of hepatic P450IIIA (CYP3A) activity. Clin Pharmacol Ther 1992:52:265-73.

33. Ged C, Rouillon JM, Pichard L. The increase in urinary excretion of $6 \beta$-hydroxycortisol as a marker of human hepatic cytochrome P450 IIIA induction. Br J Clin Pharmacol 1989;28:373-87.

34. Mostow ND, Rakita L, Vrobel TR, Noon DL, Blumer J, Amiodarone: correlation of plasma concentration with suppression of complex ventricular ectopic activity. Am J Cardiol 1984;54:569-74.
34. Roden DM. Pharmacokinetics of amiodarone: implications for drug therapy. Am J Cardiol 1993;72:45F-50F.

35. Falik R, Flores BT, Shaw L, Gibson GA, Josephson ME, Marchlinski FE. Relationship of steady-state serum concentrations of amiodarone and desethylamiodarone to therapeutic efficacy and adverse effects. Am J Med 1987;82:1102 8.

36. Brennan FJ, Brien JF, Armstrong PW. Plasma concentration time course and pharmacological effects of a standardized oral amiodarone dosing regimen in humans. Can J Cardiol 1991;7:117-24.

37. Evans SJL, Myers M, Zaher C, Simonson J, Nalos P, Vaughn C, Oseran D, Gang E, Peter T, Mandel W. High dose oral amiodarone loading: electrophysiologic effects and clinical tolerance. J Am Coll Cardiol 1992;19:169-73.

38. Holt DN, Storey GCA, McKenna WJ, Adams PC, Campbell RWF. Unwanted effects of amiodarone in relation to tissue concentration. J Am Coll Cardio $1983 ; 1: 630-9$

39. Haffajee CI, Love JC, Alpert JS, Asdourian GK, Sloan KC. Efficacy and safety of long-term amiodarone in treatment of cardiac arrhythmias: dosage experience. Am Heart J 1983;106:935-43.

Submitted March 2000.

Accepted June 2000.

MUDr. Stanislav Mičuda, Charles University in Prague, Faculty of Medicine in Hradec Králové, Department of Pharmacology, Šimkova 870, 50001 Hradec Králové, Czech Republic. e-mail: micuda@lfhk.cuni.cz 